Research Paper:

\title{
Wogonin Stimulation of Cell Death and Reducing Survivin in MDM-MB231 Breast Tumors
}

\author{
Mohammad Mehdi Adibzadeh Sereshgi ${ }^{1}$ (D), Ainaz Mashayekhi², Hassan Noorbazargan ${ }^{3 *}$ (D) \\ 1. Immunoregulation Research Center of Shahed University, Tehran. Iran. \\ 2. Department of Genetics, Student of Master Science of Genetics, School of Advanced Science and Technology, Tehran Medical Sciences, Islamic Azad \\ University, Tehran, Iran. \\ 3. Department of Biotechnology, School of Advanced Technologies in Medicine, Shahid Beheshti University of Medical Sciences, Tehran, Iran.
}

$\begin{aligned} & \text { Use vour device to scan } \\ & \text { and read the article online }\end{aligned}$
Sitation Adibzadeh Sereshgi MM, Mashayekhi A, Noorbazargan H. Wogonin Stimulation of Cell Death and Reducing
tion.4.1.2
dointhin in MDM-MB231 Breast Tumors. Immunoregulation. 2021; 4(1):33-42. http://dx.doi.org/10.32598/Immunoregula-

Article info:

Received: 03 May 2020

Accepted: 21 May 2020

Available Online: 01 Jul 2021

Keywords:

Wogonin, Apoptosis, Survivin, Breast cancer

\begin{abstract}
A B S T R A C T
Background: Wogonin as a flavonoid compound is known for its anticancer effect through growth control, differentiation, and apoptosis. This study investigates the possible activity of wogonin in inducing cell death of breast tumors MDA-MB231.

Materials and Methods: The level of cell proliferation was evaluated by MTT assay. Cycle analysis and the apoptotic rate were assessed by flow cytometry. mRNA level of Bax, Bcl-2, p53, and survivin was evaluated by real-time PCR. Western blot was utilized to assert the relative protein expression.

Results: Wogonin inhibits the proliferation of MDA-MB231 over time, and in particular, wogonin can induce the arrest of phase G1 of MDA-MB231 cells. The apoptosis of wogonin was related to a remarkable decrease in Bcl-2 and survivin and an increment in p53 and Bax. Wogonin also significantly elevated the active apoptotic forms of caspase-3, -8, -9. Z-DEVD-FMK, a specific inhibitor of caspase-3, remarkably inhibits cellular apoptosis caused by wogonin. Wogonin suppresses PI3K/Akt phosphorylation and ERK-derived phosphorylation. PD98059, a specific ERK inhibitor, significantly blocked the apoptosis caused by wogonin. Also, LY294002, a specific suppressor of PI3K, remarkably elevates the cellular apoptosis caused by wogonin. Various studies demonstrated that LY294002 not only modulates the expression of the survivin gene alone but also enhances the suppression of the expression of survivin with wogonin.
\end{abstract}

Conclusion: The apoptotic role of wogonin is observed by the triggering caspases and ERK and is associated with the suppressive pathways of the PI3K/Akt/survivin signal in the MDA-MB231 cells.

\section{"Corresponding Author:}

Hassan Noorbazargan, PhD.

Address: Department of Biotechnology, School of Advanced Technologies in Medicine, Shahid Beheshti University of Medical Sciences, Tehran, Iran.

Phone: +98 (911) 3335669

E-mail: h.noorbazargan@gmail.com 


\section{Introduction}

V

arious research studies have been proved that mammary tumor cells can be considered the most prevalent cancer among women all over the world. In the United States, nearly $10 \%$ of people experience breast cancer during their lifespan, making it the second leading cause of cancer death in women [1]. Depending on the status of cancer, standard therapeutic options such as surgery, hormone therapy, etc. However, over 40000 deaths from this cancer were determined [2]. Therefore, the search for suitable antitumor elements is even more essential for this cancer. Wogonin, with its natural flavonoid, is utilized as a reasonable factor for anticancer and chemotherapy purposes [3]. Various research studies have indicated that wogonin can suppress multiplication and stimulate cell death in multiple tumors $[4,5]$. Many mechanisms of its apoptotic effects are mainly assumed [6]. The suppression of cell cycle transfer from phase G1 to G2 and blockade of cancer metastasis is due to the suppression of phosphorylation, receptor of Vascular Endothelial Growth Factor (VEGF), and glycoprotein [7-10]. The exact pattern of the cancer is not yet clarified. Apoptosis is a growing phenomenon and a process such as the removal of unnecessary structures, damaged and harmful cells. This stage in the growth stage of blastocyst occurs during the formation of extraembryonic tissue and continues throughout organogenesis [11]. Cell death has been suggested to cure cancer [12]. Thus, apoptosis stimulation is an undeniable pathway that is contributed to the anticancer features of several anticancer agents.

The major molecular pathway involves mitochondria and the pathway of death [13]. Mitochondria are the critical location of action for family clusters of the apoptotic regulatory protein shown using Bcl-2. Three classes belong to $\mathrm{Bcl}-2$ proteins, one pro-apoptotic and the other anti-apoptotic compounds [14]. Caspases are present inside the cell in their inactive or zygomatic forms. After induction of apoptosis, these zymogenes can cleave to form active enzymes such as caspase-3. Survivin, a member of the Inhibitors of Apoptotic Protein (IAP), is adoptively expressed often in cancers and is associated with medical improvements. In various tumors, the survival of survivin is associated with anti-apoptotic pathway and is associated with elevated malignancy [15].

Besides, the protein family of serine/threonine kinases has a crucial function in cell death. MAPK/ERK and PI3K/Akt are pivotal family members. Activation of the
PI3K/Akt pathway decreases the growth of cancerous cells and apoptosis [16]. MAPK can link by adding the adjacent groups to near proteins, which act as "on" or "off" switches. ERK increases blood pressure in a direct manner [17]. The pathway of PI3K/Akt has an interesting function in the suppression of cell death via neutralizing various apoptotic proteins, including BAD (BCL2 Associated Agonist Of Cell Death) and caspase-9.

In comparison, the activation of several anti-apoptotic proteins occurs by this mechanism $[18,19]$. It is now unknown what role these two pathways play in the apoptosis of MDM-MB231 cells caused by wogonin. In this study, we evaluated whether apoptosis caused by wogonin was associated with mRNA level of PI3K/ Akt caspase-3, p53, Bcl-2, Bax, survivin, and MAPK/ ERK in MDA-MB231 tumors. It is thought that apoptosis caused by wogonin could be associated with decreased survivin and Bcl-2 regulation and activation of caspase-3. It has been suggested that wogonin induces apoptosis by activating the PI3K/Akt/survivin and MAPK/ERK pathways.

\section{Materials and Methods}

We purchased wogonin from Mabteck (Sweden), mixed with dimethyl sulfoxide (DMSO; Mabteck, Sweden). LY294002 and PD98059 were obtained from Pasteur Institute (Tehran, Iran). PD98059 and LY294002 and the polyclonal antibodies against phospho-ERK1/2, phospho-Akt, and phospho-PI3K/p85 were purchased from Mabteck, Sweden. Caspase-3 antibody (in cleavage form) was provided from Santa Cruz (USA).

\section{Cell culture}

An amount of $6.9 \times 10^{3}$ MDM-MB231 cells were seeded in a DMEM medium culture with $5 \%$ embryonic cow serum and kept in a humid atmosphere at $37^{\circ} \mathrm{C}$, two passes per week. The evaluation of cell proliferation was performed by the 2,5-diphenyl tetrazolium bromide (MTT) staining, as explained in a related study. The incubation of $7.5 \times 10^{3}$ cells was performed in the plates under different circumstances as represented. Next, six wells were adopted for $50 \mathrm{mg} / \mathrm{well}$ of MTT solution.

\section{Cell cycle assay}

When the cell confluency reached $80 \%$ (about $5 \times 10^{3}$ cells), the serum was starved for $24 \mathrm{~h}$. Then, wogonin was used to treat for $24 \mathrm{~h}$. After collecting, the washing 
step was performed with PBS twice and then centrifuged. Ethanol $70 \%(\mathrm{v} / \mathrm{v})$ was used to fix the pellet at $4^{\circ} \mathrm{C}$ for $60 \mathrm{~min}$. Then, $0.1 \mathrm{mg} / \mathrm{mL}$ RNAs A was added to the cells in PBS at $37^{\circ} \mathrm{C}$ for $30 \mathrm{~min}$. Finally, the cells were incubated in $50 \mu \mathrm{g} / \mathrm{mL}$ of Propidium Iodide (PI) solution for $30 \mathrm{~min}$ at $4^{\circ} \mathrm{C}$. The previous assay was performed based on a related kit (Mabteck, Sweden). The analysis of cells was performed by flow cytometry (Mabteck, Sweden).

\section{Apoptosis assay}

The rate of apoptosis was assessed through FACS by a related specific kit (Mabteck, Sweden). The treatment of the cells was performed with wogonin alone, or in combination with the suppressors of PD98059, ZDEVF-FMK, and LY924003, at a certain amount for overnight. Then, the collection and washing of the cells were performed twice in PBS and soaked in it. The given solution (about $100 \mu \mathrm{L}$ ) was incubated with 20 $\mu \mathrm{g} / \mathrm{mL}$ propidium iodide and annexin V-FITC at $25^{\circ} \mathrm{C}$ for $30 \mathrm{~min}$.

\section{mRNA level assessment}

The MDA-MB231 tumor was exposed to different circumstances of wogonin for $48 \mathrm{~h}$. The RNA was isolated using an isolation RNA kit (Yektatajhiz, Iran) based on the manufacturer's manual. Also, $2 \mu \mathrm{g}$ RNA was applied to transcribe mRNA into cDNA with oligo-nucleotide 18 primers and M-MLV (Mabteck, Sweden). All specific sequences for PCR were brought:

Bax: forward: 5'-AGTGTGGTGAGAGCGTCAACC-3', Reverse: 5'-AACAGAGACTCCCAGGAGAAATC-3'

BCL-2: forward: 5'-TCAGGATGCGTCCACCAAGAA-3', Reverse: 5'-TCCCGGAGGAAGTCCAATGTC-3'

Survivin: forward: 5'-GCATCCGATCCG GGGGACGGAC-3', Reverse: 5'-AAGGAAAGCGCAACCGGACGA-3'

p53: forward: 5'-TCGATACCAGACCGG GGAGG-3', Reverse: 5'-GCGCCGGTCTCTCCCAGGA-3';

GAPDH: forward: 5'-ATTCAACGGCACAGTCAAGG-3', Reverse: 5'GCAGAAGGGGCGGAGATGA-3'.
These genes were amplified at $90^{\circ} \mathrm{C}$ for $10 \mathrm{~min}$ : 30 cycles of $90^{\circ} \mathrm{C}$ for $28 \mathrm{~s}, 62^{\circ} \mathrm{C}$ for $28 \mathrm{~s}, 70^{\circ} \mathrm{C}$ for $40 \mathrm{~s}$, and $72^{\circ} \mathrm{C}$ for $8 \mathrm{~min}$.

\section{Protein assessment}

Initially, the lysis buffer was applied to disintegrate $1 \times 10^{5}$ cells. After that, the cell pellet was removed. After centrifuging at $15000 \mathrm{~g}$ for $20 \mathrm{~min}$, the isolation of proteins (equal amounts) was performed on a $10 \%$ SDS-PAGE (Mabteck, Sweden) and stopped with 0.1\% BSA overnight at $25^{\circ} \mathrm{C}$. The anti-rabbit detection antibody conjugated with Horseradish Peroxidase (HRP) (1:1000) was dispensed and kept at $37^{\circ} \mathrm{C}$ for $1 \mathrm{~h}$ before the washing step. The level of protein was measured by Thermo Fisher (USA). The relative mRNA was calculated from the ratio of the mean values of the internal gene.

\section{Statistical analysis}

All experiments were carried out, and the mean values of test results were used for analysis. One-way ANOVA compared the obtained values between experimental groups. Prism 6.0 software was applied for analysis. The findings were considered significant when the $\mathrm{P}$ value was less than 0.05 . Also, data were normalized to glyceraldehyde-3-phosphate dehydrogenase level as the reference gene. The relative expression of the mRNA genes was measured with the $\Delta \mathrm{CT}$ assay.

\section{Results}

The suppression and pro-apoptotic activities of wogonin on MDM-MB231 cells

Earlier studies indicate that wogonin has a suppressor role on various tumor cells. Herein, we appraised whether wogonin can suppress the proliferation of MDM-MB231 cells. Wogonin suppressed the MDMMB231 tumors in a time- and dose-dependent manner. The mean \pm SD IC50 levels for $48 \mathrm{~h}$, and $72 \mathrm{~h}$ were $89.24 \pm 3.39 \mu \mathrm{M}$ and $69.28 \pm 3.12 \mu \mathrm{M}$, respectively. To study if wogonin suppression of tumor growth was because of cell cycle cessation, we assessed the cell ratio in various cell cycles (Figure 1). The cells in G0/ G1 were remarkably elevated, but cells in the S phase were reduced by incubation with wogonin. Also, the role of wogonin on cell death of MDM-MB231 tumors was evaluated by flow cytometry (Figure 2A and B). As well, Figure 2C and D demonstrate the elevation of apoptosis percentage. Wogonin stimulated a remarkable increment in the late and early cell death at the 


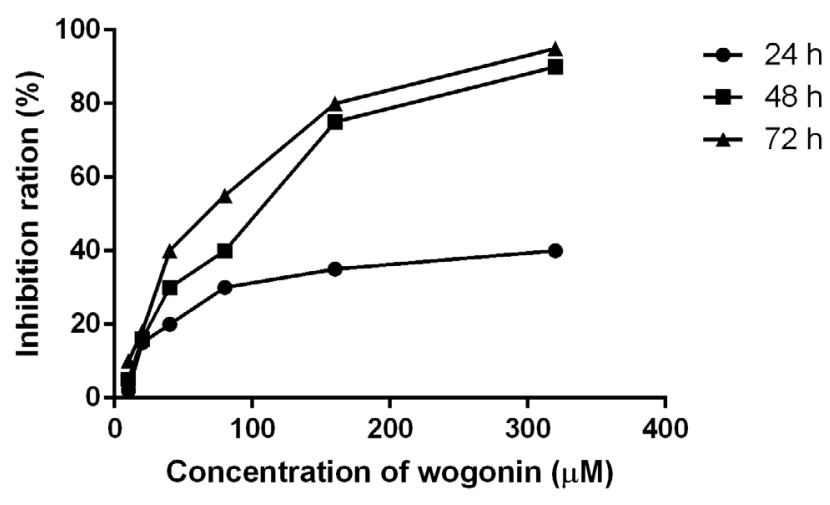

Figure 1. Suppressor role of wogonin on the development of MDA-MB231 cells

$7.5 \times 103$ cells were measured with multiple doses of wogonin for $24 \mathrm{~h}, 48 \mathrm{~h}$, and $72 \mathrm{~h}$. The suppression level was measured. The cytotoxicity level was evaluated by MTT assay. Regression analysis was used to calculate IC50 values.

dose of $90 \mu \mathrm{M}$. The result showed $17.37 \%$ as apoptotic cell percentages. Figure 2D and E, demonstrate that as time passed, the level of apoptosis elevated remarkably.

\section{Apoptotic gene modulation}

The IAP and Bcl-2 protein families have an essential role in balancing anti-apoptotic processes and send death signals to assert cell fate [16]. To assess the activity of the Bcl-2 family in the intermediate apoptosis of wogonin, we examined the mRNA level of the anti-apoptotic of Bcl-2, survivin, and pro-apoptosis p53 and Bax using Western blot and RT-PCR. As demonstrated in Figure 3 , the gene expression and the level of protein of Bax were elevated after $48 \mathrm{~h}$ in cells incubated with $85 \mu \mathrm{M}$ wogonin, while the levels of Bcl-2 reduced remarkably. The increment of the $\mathrm{Bax} / \mathrm{Bcl}-2$ ratio compared to the control was observed at $90 \mu \mathrm{mol} / \mathrm{L}$ concentration of wogonin. The wogonin treatment also reduced the concentration of mRNA and residual protein. The results of p53 protein and gene expression levels were remarkably upregulated in treatment with wogonin.

\section{Caspases assay}

The crucial modulators of apoptosis belong to a certain group of compounds called caspases [21]. Our research evaluated the wogonin role on caspases. Figure $4 \mathrm{~A}$ and $\mathrm{B}$ demonstrated that the wogonin treatment led to stimulation of activated shape of caspases- $8,-9$, and -3 at a certain concentration. To approve if wogoninstimulated apoptosis was caspase-3-dependent, we used Z-EDVE-FMK, a caspases-3 suppressor, to block caspases-3 function. Wogonin remarkably elevated the caspase- 3 activity, and the analysis of flow cytometry showed that Z-EDVE-FMK alone could not affect cell apoptosis; however, it significantly suppressed wogonin-stimulated apoptosis in MDM-MB231 tumors.

\section{PI3K/Akt and MAPK/ERK}

We evaluated the effect of wogonin on the MAPK/ ERK and PI3K/Akt pathways for approving the apoptosis mechanism. The findings of the western blotting assay demonstrated that the phosphorylation form of PI3K/Akt (p-PI3K/p-Akt) reduced after treating with wogonin for $24 \mathrm{~h}$ and more inhibited after $48 \mathrm{~h}$ treatment. The protein level of PI3K was reduced, while Akt remained constant with the treatment of wogonin. The survivin expression was remarkably reduced after incubation for $48 \mathrm{~h}$. The ERK activation showed via p-ERK (in the form of phosphorylation) was recorded after incubation with wogonin (Figure 5A and B). To determine if apoptosis caused by wogonin is related to the PI3K/Akt signaling pathway, we investigated the effect of LY294002, a PI3K suppressor, in apoptosis. The analysis of flow cytometry showed that the combined incubation of LY294002 and wogonin enhances the suppressor function. PD98059, a specific ERK suppressor, is weak for apoptosis caused by wogonin in MDA-MB231 cells (Figure 5C). The findings of western blotting results demonstrated that the cleaved caspase-3 sharply elevated in the combined incubation of LY294002 and wogonin (Figure 5E). The earlier study demonstrated that wogonin could inhibit the protein level in survivin. To determine whether PI3K/Akt signaling pathway is participated in modulating survivin, we assessed the effect of the signal suppressor on the mRNA level of survivin (Figure 5D). More research demonstrated that wogonin could inhibit the levels of survivin, p-Akt, and p-PI3K. Analysis of mRNA level indicated that LY294002 increased the inhibitory effect of wogonin on the survivin (Figure 5E). 


$\begin{array}{lcccc}\text { A Wogonin } & \text { Go/G1 (\%) } & \text { S(\%) } & \text { G2/M (\%) } & \text { Apoptosis (\%) } \\ \text { Control } & 64.84 \pm 2.5 & 26.74 \pm 1.2 & 8.42 \pm 1.3 & 2.19 \pm 0.21 \\ 30 & 68.86 \pm 3.2 & 23.62 \pm 2.1 & 7.66 \pm 1.4 & 5.04 \pm 0.56 \\ 60 & 69.84 \pm 2.6 & 15.73 \pm 1.6 & 14.46 \pm 1.1 & 8.52 \pm 0.74 \\ 90 & 75.73 \pm 2.8 & 15.25 \pm 1.7 & 9.02 \pm 1.1 & 10.39 \pm 1.10\end{array}$

B
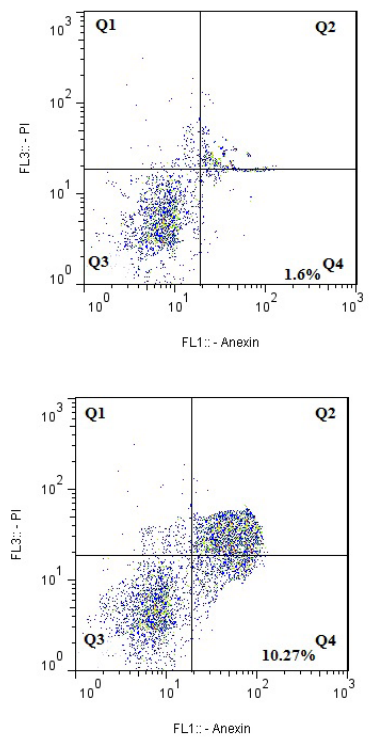

D

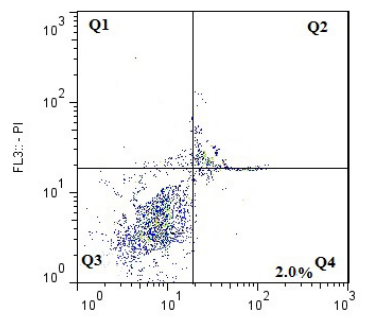

FL1:- Anexin

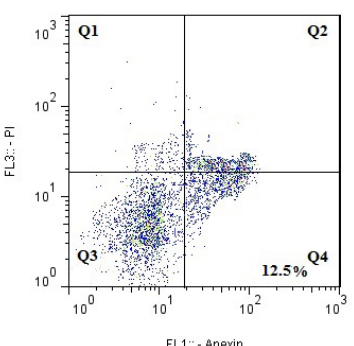

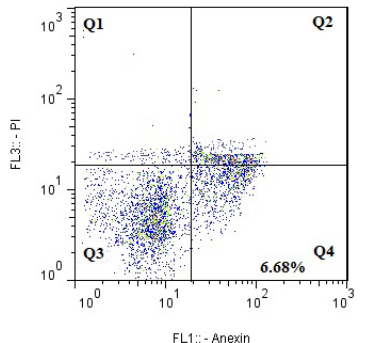

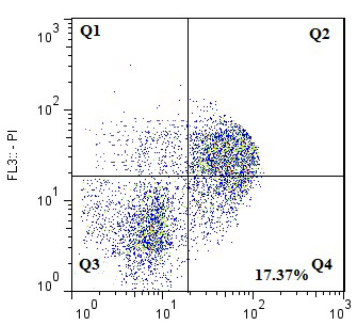

FL1:. - Anexin

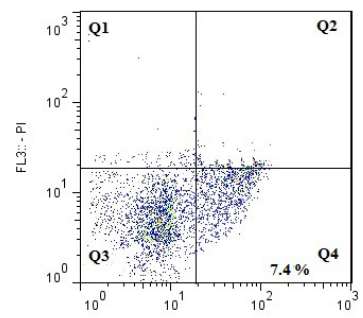

FL1:- Anexin

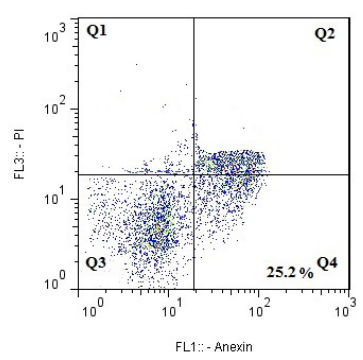

C

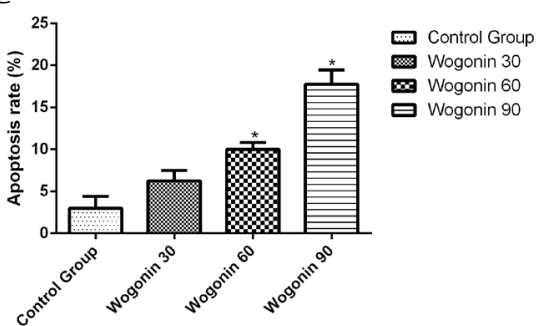

E

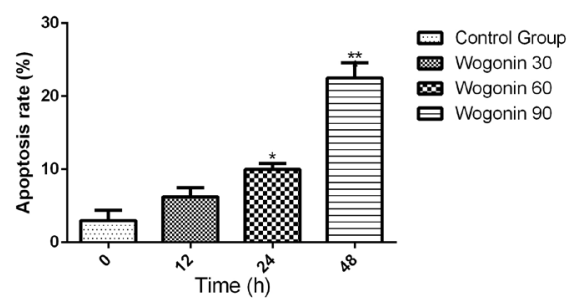

Figure 2. The wogonin effect on apoptosis and cell cycle in MDA-MB231 $(5 \times 103)$

IMMUNoReGULATION

A: The statistical findings of cell cycle; B: Wogonin resulted in potential apoptosis in MDA-MB231 cells after incubation with multiple doses of wogonin for $24 \mathrm{~h}$; C: The findings of FACS assessment; D: Wogonin stimulated cell death after incubation several times at $60 \mu \mathrm{mol} / \mathrm{L} ; \mathrm{E}$ : Apoptosis rate. The data were analyzed by Graphpad Prism. ${ }^{*} \mathrm{P}<0.05$ vs the control group. 
A

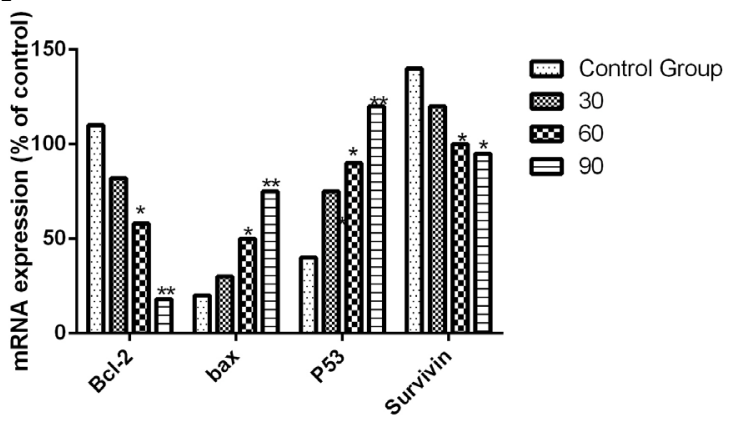

B

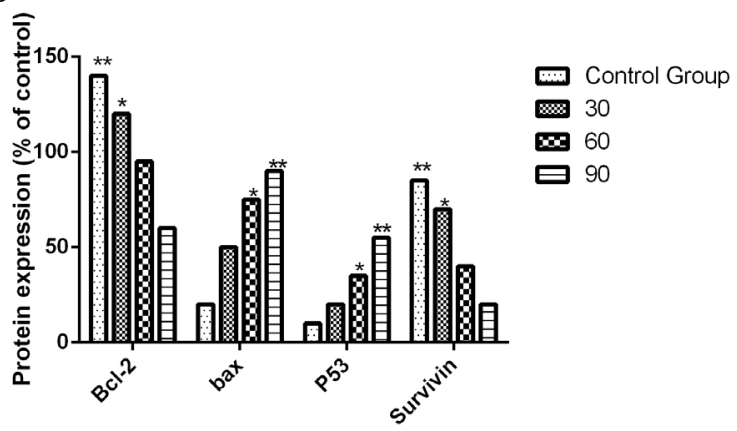

IMMUNoREgulation

Figure 3. Wogonin affecting the protein level and mRNA of pro- and anti-apoptosis proteins in MDA-MB231 tumors

A: The quantitative findings of mRNA level; B:The quantitative findings of protein levels; Analysis of data was performed by Rest software.

\section{Discussion}

Ancient Chinese medicine has recently been studied as a novel mediator of anticancer agents [22]. Until now, researchers have tried to find compounds that can significantly induce cancer cell apoptosis. Maximizing efficiency by minimizing the adverse effects has become a key aim in detecting apoptosis stimulators [23]. Various studies have shown that plant flavonoids have strong anticancer and anti-inflammatory features [24]. Wogonin is a good candidate because of its antitumor role and less cytotoxicity [20]. In the present project, we initially evaluated whether wogonin stimulated apoptosis in MDM-MB231 tumors. It was shown that wogonin could suppress cell proliferation. The finding of the flow cytometry assay showed that wogonin could stimulate cell apoptosis dose- and time-dependently.

While, in reaction to the treatment of wogonin, the cell cycle was suppressed in the G0/G1 phase. The findings show that inhibition of wogonin due to cell proliferation involves cell cycle inhibition. The main approaches include molecular and mitochondrial pathways and receptors which are associated with cell death. Bcl-2 is an apoptosis suppressor. The protein level of Bcl-2 suppresses the mitochondrial pathways. The alteration in Bax/Bcl-2 stimulates the molecular pathway of caspase $[25,26]$. Elevated p53 enhances Bax directly, which affects the mitochondria integrity to stimulate cell death [27]. Apoptosis and cell division were inhibited by survivin as a multifunctional protein [28]. Survivin can suppress the triggering of activated caspase- 7 and caspase-3, affecting a usual downstream of intrinsic and extrinsic apoptosis molecular pathways [29]. Our results showed that wogonin reduced survivin and Bcl2 in the mRNA level and elevated the expression of p53 and Bax. Caspases can be classified based on the
$\mathrm{N}$ terminal: caspases with a long domain are the primary to be activated in response to apoptosis inducers [30]. In the present research, a remarkable increase in the mRNA level and function of caspases-3, -8, -9 were reported after exposure to wogonin. Caspase- 3 can be deemed an essential member among the caspases.

The special suppressor of caspase-3 Z-EDVE-FMK could prevent the apoptosis caused by wogonin, indicating that caspase- 3 has a pivotal function in apoptosis caused by wogonin. As mentioned above, it shows that we are regulating Bcl-2 and supporting survivin, which can regulate caspase-3 and apoptosis from MDAMB231 cells. PI3K/Akt is an essential signaling pathway in apoptosis, growth, and cell proliferation. Akt is the main downstream PI3K target [31]. The PI3K/Akt molecular pathway promotes the growth and progression of multiple tumors by elevating Akt's activity. Activated phosphorylation, which is needed to suppress tumors progression and apoptosis, is applied as a reading to activate Akt [32]. The PI3K/Akt signaling pathway suppresses apoptosis through disabling interesting clusters of the apoptosis cascade such as caspase-9, proponents of bad apoptosis [33], and survivin [34]. The activation of the ERK molecular pathway occurs in response to survival factors [35]. But, novel research has shown that stable activation of ERK also plays a role in apoptosis. Intense ERK stimulation has been observed to suppress the cell cycle and mediate apoptosis through regulation of the expression of Fas ligand expression [36, 37]. We found that wogonin lowers PI3K/ Akt and survivin settings and activates ERK.

In comparison, the mRNA level of survivin has declined remarkably after the maximum low p-Akt and P-PI3K settings. More findings indicated that the PI3K suppressor LY294002 increased the effects of wogonin 
A
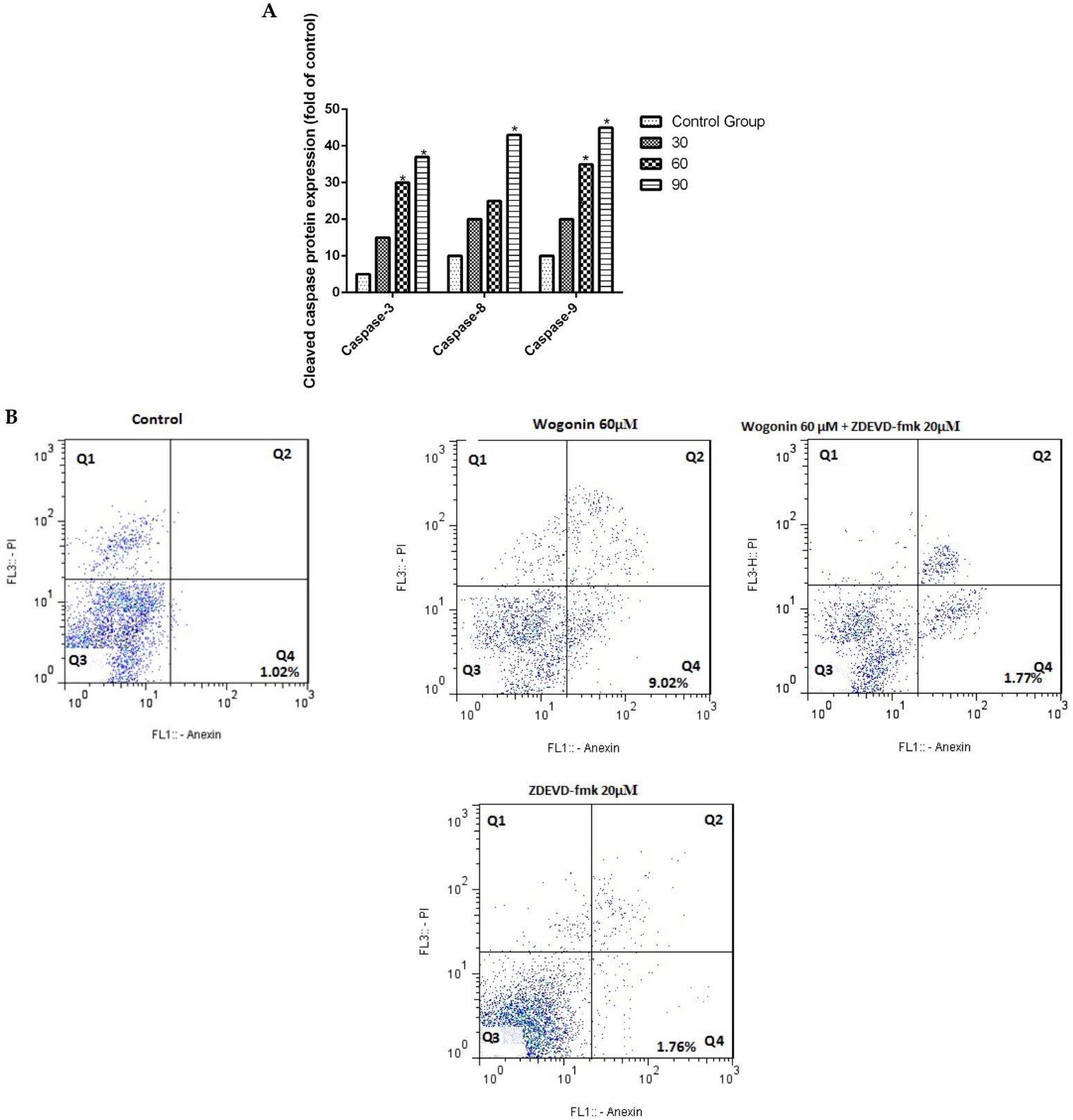

Figure 4. The incubation with wogonin stimulated the activation of Caspases in MDA-MB231 tumors

IminunoRegulation

A: The assessment of activated Caspases after incubation with wogonin, considerable variations between wogonin-incubated group and the control assessed by Dennett's test and demonstrated by Asterisks; B: Caspases-3 specific suppressor Z-DEVDFMK suppressed the apoptosis stimulated via wogonin.

One-way ANOVA test was used to analyses data by flow cytometry.

The data are represented as Mean $\pm \mathrm{SD}$. ${ }^{*} \mathrm{P}<0.05$ vs the control group.

on inhibition of survivin and increased the active form of cleaved caspase-3. Our results demonstrate that survivin inhibition is mediated by the inactivation of PI3K/ Akt in cells treated with wogonin-MDM-MB231. In addition, apoptosis caused by wogonin was weakened by PD98059 after inhibiting the MAPK/ERK pathway.

\section{Conclusion}

In the present project, it has been concluded that wogonin apoptosis was caused by MDM-MB231 human breast cancer cells. Bax, p53 can regulate the apoptosis pathway and caspase- 3 activation decreased BCL2 and survivin modulation. Furthermore, both pathways of MAPK/ERK and PI3K/Akt pivotal had 
A

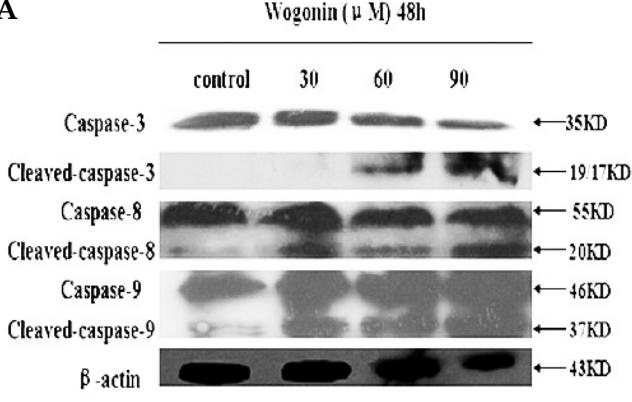

B $\overline{\overline{0}}$

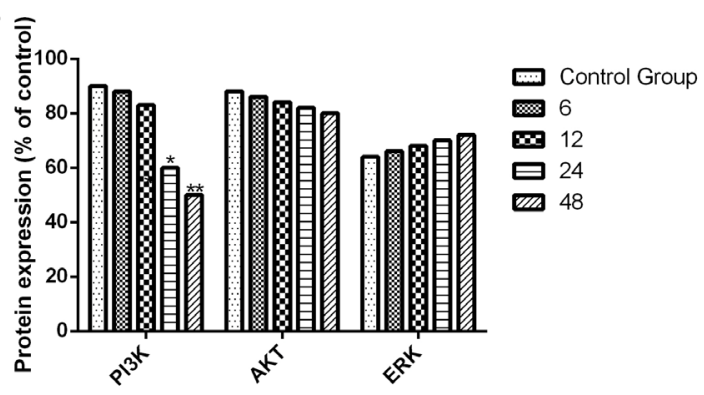

C

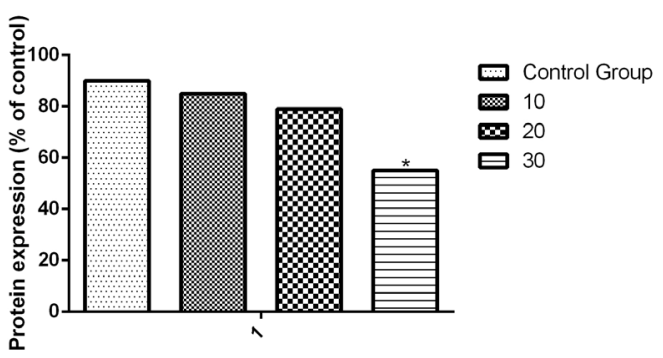

D
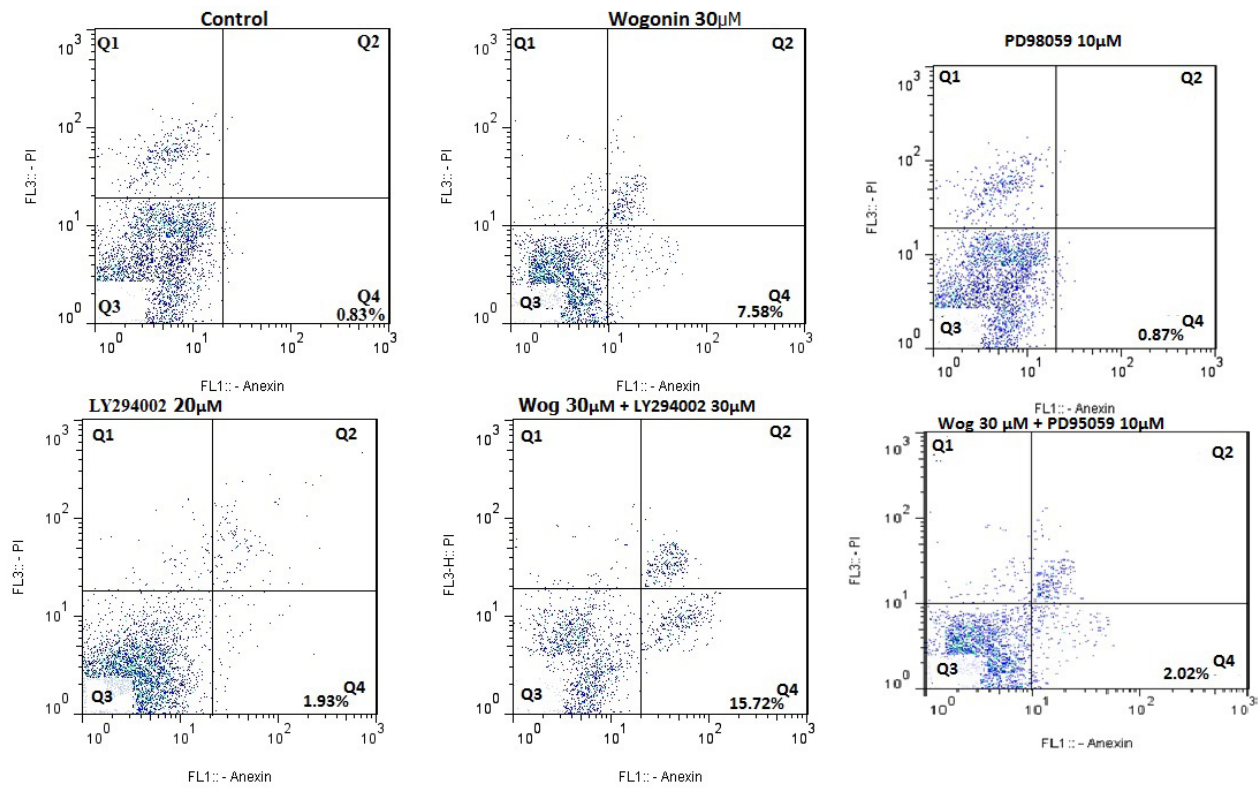

E

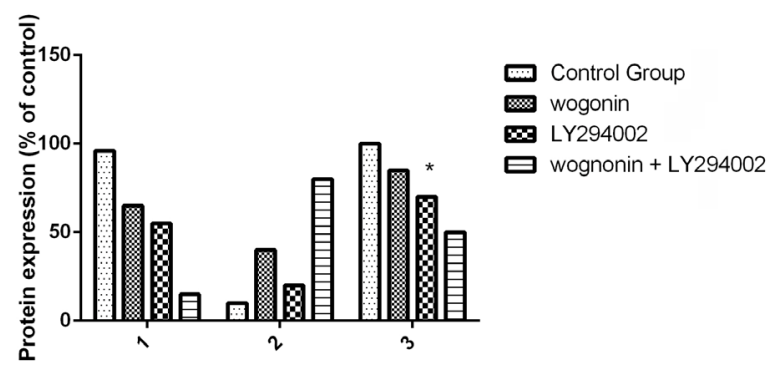

IMMUNoRegulatios

Figure 5. 1×106 MDA-MB231 cells assessed for western blotting assay, wogonin-stimulated apoptosis contributed to both pathways of MAPK/ERK and PI3K/Akt/survivin in MDA-MB231

A: The MDA-MB231 incubated with 80 Mm wogonin, while ERK, Akt, p-Akt, p-ERK, PI3K, p-PI3K, and survivin were observed via western blotting analysis; B: The quantitative findings of associated proteins after incubation with wogonin; C: The role of kinase suppressors on wogonin-stimulated apoptosis in MDA-MB231 tumors, the apoptosis level reported via flow cytometry after expose to wogonin, LY294002, Wogonin+PD98059, Wogonin+LY294002, and PD98059, respectively for 24 h; D: PI3K suppressor LY294002 decreased the mRNA level of survivin; E: PI3K suppressor LY294002 increased wogonin stimulation decrease of survivin and p-Akt mRNA level, and promoted wogonin-stimulated activation of Caspases-3. ${ }^{*} \mathrm{P}<0.05$ vs the control group. 
an essential activity on wogonin-stimulated apoptosis of MDM-MB231 cells. Suppression of the PI3K/Akt pathway through wogonin could be used for expressing the survivin rate of a downstream PI3K/Akt pathway target. Our findings indicated the molecular signaling pathway of the antitumor function of wogonin.

\section{Ethical Considerations}

\section{Compliance with ethical guidelines}

There were no ethical considerations to be considered in this research.

Funding

This research did not receive any grant from funding agencies in the public, commercial, or non-profit sectors.

\section{Authors' contributions}

Conceptualization, methodology: Mohammad Mehdi Adibzadeh Sereshgi and Hassan Noorbazargan; Data analysis: Ainaz Mashayekhi; Write original draft: Mohammad Mehdi Adibzadeh Sereshgi; Writing and review: All authors.

\section{Conflicts of interest}

The authors declared no conflict of interest.

\section{Acknowledgements}

We want to thank ARK Research Laboratory and its staff for performing this research project.

\section{References}

[1] Luo M, Guan JL. Focal adhesion kinase: A prominent determinant in breast cancer initiation, progression and metastasis. Cancer Letters. 2010; 289(2):127-39. [DOI:10.1016/j. canlet.2009.07.005] [PMID] [PMCID]

[2] Jemal A, Siegel R, Ward E, Hao Y, Xu J, Thun MJ. Cancer statistics, 2009. CA: A Cancer Journal for Clinicians. 2009; 59(4):225-49. [DOI:10.3322/caac.20006] [PMID]

[3] Zhao Q, Wang J, Zou MJ, Hu R, Zhao L, Qiang L, et al Wogonin potentiates the antitumor effects of low dose 5-fluorouracil against gastric cancer through induction of apoptosis by down-regulation of NF-kappaB and regulation of its metabolism. Toxicology Letters. 2010; 197(3):20110. [DOI:10.1016/j.toxlet.2010.05.019] [PMID]
[4] Himeji M, Ohtsuki T, Fukazawa H, Tanaka M, Yazaki SI, Ui S, et al. Difference of growth-inhibitory effect of Scutellaria baicalensis-producing flavonoid wogonin among human cancer cells and normal diploid cell. Cancer Letters. 2007; 245(1-2):269-74. [DOI:10.1016/j.canlet.2006.01.011] [PMID]

[5] Wang W, Guo QL, You QD, Zhang K, Yang Y, Yu J, et al The anticancer activities of wogonin in murine sarcoma S180 both in vitro and in vivo. Biological and Pharmaceutical Bulletin. 2006; 29(6):1132-7. [DOI:10.1248/bpb.29.1132] [PMID]

[6] Parajuli P, Joshee N, Chinni SR, Rimando AM, Mittal S, Sethi S, et al. Delayed growth of glioma by Scutellaria flavonoids involve inhibition of Akt, GSK-3 and NF-kB signaling. Journal of Neuro-Oncology. 2011; 101(1):15-24. [DOI:10.1007/s11060-010-0221-x] [PMID] [PMCID]

[7] Lee E, Enomoto R, Koshiba Ch, Hirano H. Inhibition of Pglycoprotein by wogonin is involved with the potentiation of etoposide-induced apoptosis in cancer cells. Annals of the New York Academy of Sciences. 2009; 1171(1):132-6. [DOI:10.1111/j.1749-6632.2009.04722.x] [PMID]

[8] Lu N, Gao Y, Ling Y, Chen Y, Yang Y, Gu HY, et al. Wogonin suppresses tumor growth in vivo and VEGF-induced angiogenesis through inhibiting tyrosine phosphorylation of VEGFR2. Life Sciences. 2008; 82(17-18):956-63. [DOI:10.1016/j.lfs.2008.02.013] [PMID]

[9] Parajuli P, Joshee N, Rimando AM, Mittal S, Yadav AK. In vitro antitumor mechanisms of various Scutellaria extracts and constituent flavonoids. Planta Medica. 2009; 75(1):418. [DOI:10.1055/s-0028-1088364] [PMID]

[10] Yang L, Zhang HW, Hu R, Yang Y, Qi Q, Lu N, et al Wogonin induces $G_{1}$ phase arrest through inhibiting Cdk4 and cyclin D1 concomitant with an elevation in p21 ${ }^{\text {ip1 }}$ in human cervical carcinoma HeLa cells. Biochemistry and Cell Biology. 2009; 87(6):933-42. [DOI:10.1139/O09-060] [PMID]

[11] Woo GH, Bak EJ, Nakayama H, Doi K. Molecular mechanisms of hydroxyurea (HU)-induced apoptosis in the mouse fetal brain. Neurotoxicology and Teratology. 2006; 28(1):125-34. [DOI:10.1016/j.ntt.2005.08.002] [PMID]

[12] Kelloff GJ, Crowell JA, Steele VE, Lubet RA, Malone WA, Boone $\mathrm{CW}$, et al. Progress in cancer chemoprevention: Development of diet-derived chemopreventive agents. The Journal of Nutrition. 2000; 130(2):467S-71. [DOI:10.1093/ jn/130.2.467S] [PMID]

[13] Hengartner MO. The biochemistry of apoptosis. Nature 2000; 407(6805):770-6. [DOI:10.1038/35037710] [PMID]

[14] Bishopric NH, Andreka P, Slepak T, Webster KA. Molecular mechanisms of apoptosis in the cardiac myocyte. Current Opinion in Pharmacology. 2001; 1(2):141-50. [DOI:10.1016/S1471-4892(01)00032-7]

[15] Altieri DC. Survivin, versatile modulation of cell division and apoptosis in cancer. Oncogene. 2003; 22(53):8581-9. [DOI:10.1038/sj.onc.1207113] [PMID]

[16] Moon DO, Lee KJ, Choi YH, Kim GY. $\beta$-Sitosterolinduced-apoptosis is mediated by the activation of ERK and the downregulation of Akt in MCA-102 murine fibrosarcoma cells. International Immunopharmacology. 2007; 7(8):1044-53. [DOI:10.1016/j.intimp.2007.03.010] [PMID] 
[17] Bueno OF, De Windt LJ, Tymitz KM, Witt SA, Kimball TR, Klevitsky R, et al. The MEK1-ERK1/2 signaling pathway promotes compensated cardiac hypertrophy in transgenic mice. The EMBO Journal. 2000; 19(23):6341-50. [DOI:10.1093/emboj/19.23.6341] [PMID] [PMCID]

[18] Cardone MH, Roy N, Stennicke HR, Salvesen GS, Franke TF, Stanbridge E, et al. Regulation of cell death protease caspase- 9 by phosphorylation. Science. 1998; 282(5392):1318-21. [DOI:10.1126/science.282.5392.1318] [PMID]

[19] Vivanco I, Sawyers CL. The phosphatidylinositol 3-kinase-AKT pathway in human cancer. Nature Reviews Cancer. 2002; 2(7):489-501. [DOI:10.1038/nrc839] [PMID]

[20] Enomoto R, Koshiba Ch, Suzuki Ch, Lee E. Wogonin potentiates the antitumor action of etoposide and ameliorates its adverse effects. Cancer Chemotherapy and Pharmacology. 2011; 67(5):1063-72. [DOI:10.1007/s00280-0101396-8] [PMID]

[21] Bhardwaj A, Aggarwal BB. Receptor-mediated choreography of life and death. Journal of Clinical Immunology. 2003; 23(5):317-32. [DOI:10.1023/A:1025319031417] [PMID]

[22] Li-Weber M. New therapeutic aspects of flavones: The anticancer properties of Scutellaria and its main active constituents Wogonin, Baicalein and Baicalin. Cancer Treatment Reviews. 2009; 35(1):57-68. [DOI:10.1016/j. ctrv.2008.09.005] [PMID]

[23] Baumann S, Fas SC, Giaisi M, Müller WW, Merling A, Gülow K, et al. Wogonin preferentially kills malignant lymphocytes and suppresses T-cell tumor growth by inducing PLC 11 - and $\mathrm{Ca}^{2+}$-dependent apoptosis. Blood. 2008; 111(4):2354-63. [DOI:10.1182/blood-2007-06-096198] [PMID]

[24] Wang CZ, Li XL, Wang QF, Mehendale SR, Yuan CS. Selective fraction of Scutellaria baicalensis and its chemopreventive effects on MCF-7 human breast cancer cells. Phytomedicine. 2010; 17(1):63-8. [DOI:10.1016/j. phymed.2009.07.003] [PMID] [PMCID]

[25] Kirkin V, Joos S, Zörnig M. The role of Bcl-2 family members in tumorigenesis. Biochimica et Biophysica Acta (BBA) - Molecular Cell Research. 2004; 1644(2-3):229-49. [DOI:10.1016/j.bbamcr.2003.08.009] [PMID]

[26] Manion MK, Hockenbery D. Targeting Bcl-2 related proteins in cancer therapy. Cancer Biology \& Therapy. 2003; 2(sup1):104-13. [DOI:10.4161/cbt.209]

[27] Chipuk JE, Kuwana T, Bouchier-Hayes L, Droin NM, Newmeyer DD, Schuler M, et al. Direct activation of Bax by p53 mediates mitochondrial membrane permeabilization and apoptosis. Science. 2004; 303(5660):1010-4. [DOI:10.1126/science.1092734] [PMID]

[28] Li F, Ambrosini G, Chu EY, Plescia J, Tognin S, Marchisio PC, et al. Control of apoptosis and mitotic spindle checkpoint by survivin. Nature. 1998; 396(6711):580-4. [DOI:10.1038/25141] [PMID]

[29] Suzuki A, Ito T, Kawano H, Hayashida M, Hayasaki Y, Tsutomi $Y$, et al. Survivin initiates procaspase 3/p21 complex formation as a result of interaction with $\mathrm{Cdk} 4$ to resist Fas-mediated cell death. Oncogene. 2000; 19(10):1346-53. [DOI:10.1038/sj.onc.1203429] [PMID]
[30] Riedl SJ, Shi Y. Molecular mechanisms of caspase regulation during apoptosis. Nature Reviews Molecular Cell Biology. 2004; 5(11):897-907. [DOI:10.1038/nrm1496] [PMID]

[31] Kauffmann-Zeh A, Rodriguez-Viciana P, Ulrich E, Gilbert Ch, Coffer P, Downward J, et al. Suppression of c-Myc-induced apoptosis by Ras signalling through PI(3)K and PKB. Nature. 1997; 385(6616):544-8. [DOI:10.1038/385544a0] [PMID]

[32] Luo J, Manning BD, Cantley LC. Targeting the PI3K-Akt pathway in human cancer: Rationale and promise. Cancer Cell. 2003; 4(4):257-62. [DOI:10.1016/S1535-6108(03)002484]

[33] Brunet A, Bonni A, Zigmond MJ, Lin MZ, Juo P, Hu LS, et al. Akt promotes cell survival by phosphorylating and inhibiting a forkhead transcription factor. Cell. 1999; 96(6):857-68. [DOI:10.1016/S0092-8674(00)80595-4]

[34] Kim S, Kang J, Qiao J, Thomas RP, Evers BM, Chung DH. Phosphatidylinositol 3-kinase inhibition down-regulates survivin and facilitates TRAIL-mediated apoptosis in neuroblastomas. Journal of Pediatric Surgery. 2004; 39(4):51621. [DOI:10.1016/j.jpedsurg.2003.12.008] [PMID]

[35] Keshet $Y$, Seger R. The MAP kinase signaling cascades: A system of hundreds of components regulates a diverse array of physiological functions. In: Seger R, editor. MAP Kinase Signaling Protocols. Methods in Molecular Biology (Methods and Protocols). Vol 661. Totowa, NJ: Humana Press; 2010. pp. 3-38. [DOI:10.1007/978-1-60761-795-2_1] [PMID]

[36] Plotkin LI, Mathov I, Aguirre JI, Parfitt AM, Manolagas SC, Bellido T. Mechanical stimulation prevents osteocyte apoptosis: Requirement of integrins, Src kinases, and ERKs. American Journal of Physiology-Cell Physiology. 2005; 289(3):C633-43. [DOI:10.1152/ajpcell.00278.2004] [PMID]

[37] Tantini B, Pignatti C, Fattori M, Fiumana E, Facchini A, Stefanelli C, et al. Polyamine depletion inhibits etoposideinduced NF-KB activation in transformed mouse fibroblasts. Amino Acids. 2004; 27(2):207-14. [DOI:10.1007/ s00726-004-0101-9] [PMID] 